\title{
Challenges Faced by Primary School Teachers in Implementing the Automatic Promotion Policy at a School in the Zambezi Region
}

\author{
Bollen Mukela Chataa, David Nkengbeza \\ University of Namibia, Windhoek, Namibia \\ Email: bchataa@unam.na,dnkengbeza@unam.na
}

How to cite this paper: Chataa, B. M. \& Nkengbeza, D. (2019). Challenges Faced by Primary School Teachers in Implementing the Automatic Promotion Policy at a School in the Zambezi Region. Creative Education, 10, 1731-1744.

https://doi.org/10.4236/ce.2019.107123

Received: September 18, 2018

Accepted: July 28, 2019

Published: July 31, 2019

Copyright (c) 2019 by author(s) and Scientific Research Publishing Inc. This work is licensed under the Creative Commons Attribution International License (CC BY 4.0).

http://creativecommons.org/licenses/by/4.0/

\begin{abstract}
Prior to independence in 1990, learners were expected to meet all the pass requirements of a given grade before proceeding to the next grade level as a matter of policy. Learners who failed a grade were to repeat at the same or different school. In the case where parents of the learner chose to take their kid to a different school, such a learner was to go with a transfer letter, clearly stating the status of the learner, signed by the school principal or someone designated by him. It did not matter how many times the learner failed and repeated a grade. What was required is that each learner should meet the pass requirements of a grade before being allowed to proceed to the next grade. At independence, a new policy called automatic or social promotion was introduced in the education system of Namibia as part of the education reform. This policy, as the name suggests, requires a learner who failed a grade for the second time to be transferred or promoted to the next grade despite not having met the minimum pass requirements of that grade. The study employed a qualitative approach in order to gain insight into the issue being investigated. Data were collected by interviewing only those teachers who once taught or are currently teaching learners who were promoted automatically to their new grades. Data were analyzed by identifying salient themes and recurring ideas and classifying them into categories to make sense of the data. The study revealed that bullying other learners, poor academic performance of the promoted learners, truancy and lack of time to assist other learners were the major challenges primary school teachers at the selected school in the Zambezi Education Region face in implementing the automatic promotion policy.
\end{abstract}

\section{Keywords}

Automatic Promotion Policy, Retention, Culture of Entitlement, Achievement and Assessment Challenges 


\section{Introduction}

At the dawn of independence, Namibia, through the newly created Ministry of Education, Culture, Youth and Sports (MECYS), embarked upon a major education reform by introducing education policies in line with the new political dispensation. One of such policy changes was the way in which learners would progress from one grade to the other and the status of those who failed to meet the pass requirements of a given grade. Prior to independence, a learner who failed a grade was required to repeat the grade before he/she could proceed to the next grade level. In the document entitled, "The National Assessment Policy for Schools in South West Africa", (Department of National Education 1980: p. 10) it is stated that the pass requirements for any examination should be met before a pupil is transferred to the next standard. Any pupil who failed a standard was required to repeat that standard before he/she could proceed to the next level.

However, this policy and practice changed soon after the attainment of independence in 1990. The new policy, known as automatic promotion, allows a learner who failed to repeat a grade only once (Zeichner, 1996). If a learner fails a grade for the second time he/she should automatically be transferred or promoted to the next grade. The document entitled, The Revised Pilot Curriculum Guide for Formal Basic Education confirms that: "No learner shall repeat more than once in the Lower Primary phase and more than once in the Upper Primary phase" (Ministry of Education, 2005: p. 2).

In the circular entitled, "Requirements for Promotion of Learners in Grades 1 - 9 and 11 and Compulsory Compensatory Teaching", Ministry of Education (2005: p. 6) states that:

No learner shall in total repeat more than once at the lower primary level, i.e. grades 1 - 4. A learner, who does not comply with the minimum promotion requirements for the second time, must be transferred to the next grade. Transferred learners should receive compulsory compensatory teaching in the next grade. Similarly, no learner shall in total repeat more than once at upper primary level, i.e. Grades 5 - 7. A learner, who does not comply with the minimum promotion requirements for the second time, must be transferred to the next grade level (Ministry of Education, 2005: p. 6).

However, people from different walks of life, including educationists, teachers' unions, students' organizations, and those from the business sector have expressed their dissatisfaction on the policy. For example, in a publication entitled, "On the education crisis", Pupkewitz (2006: p. 7) wrote:

Automatic promotion in our schools has produced a culture of entitlement, a belief that time served is the same as productive use of time. If a learner fails a class, he/she should not be automatically promoted since not only will he/she hold back the group's learning at a higher level, the lesson of reward for hard work is ignored (Pupkewitz, 2006: p. 7).

The Namibian National Students' Organization (NANSO, 2009) also commented on the Grade 8 results, saying that the education system was a "...time 
bomb..." ready to explode, and blamed among other things, the automatic promotion of learners.

\subsection{Background of the Study}

The study was carried out at a school in the Katima Mulilo Circuit in the Zambezi Education Region of Namibia. The region is one of the fourteen education regions of the country and situated in the far north-east of the country. As stated earlier, the policy of automatic promotion was introduced shortly after independence and has been in force since then.

At the time of independence, in 1990, the country inherited an education system that was operating according to apartheid policies and practices. Apartheid was a system based on legal separation of races which was introduced in South Africa by the National Party when it came to power in 1948 (Mbumba \& Noise, 1988). These apartheid policies and practices were also introduced in Namibia when South Africa took control of the country.

Learners who failed a standard had to repeat it or drop out of school. This naturally resulted in high numbers of repeaters (Shilongo, 2004). Those learners who failed a supplementary examination had no choice but to repeat the whole academic year. It did not matter how many times a learner repeated a grade, what was required was that all learners should meet the pass requirements of a grade before proceeding to the next grade after passing the year-end examination (Shilongo, 2004). A learner who failed a grade had two options. First, the learner had to repeat the grade, either at the same school or at a different school. If the learner chose to repeat the grade at a different school, he/she was required, as a matter of policy, to present a transfer letter to the school which clearly stated the promotion status of the learner. The National Education Act, No. 30 (Department of National Education, 1980) indicated that any learner who failed a grade and wanted to transfer to another school should obtain a transfer letter signed by the school principal or someone delegated by him, and submit it at his/her new school. Alternatively, the learner could drop out of school and join the family activities, or seek employment. This paper investigated the challenges primary school teachers at the selected school face as a result of the automatic promotion policy.

\subsection{Problem Statement and Research Question}

Many researchers, like Aldridge and Goldman (1999) argue that one of the most important benefits of promoting a learner who is not academically capable of functioning at a particular grade level to a higher grade is giving that particular learner an opportunity to have learners of his/her age group as role models in the class. Automatic promotion is done so as not to harm the learners' self-esteem, to keep the learners together by age (in the same age cohort), to facilitate learners' involvement in sport teams, and to allow learners who are strong in one area, but weak in another, to advance in the strong area (Griffith, 2006). 
The problem that underlies this study focuses on the challenges primary school teachers at the selected school in the Katima Circuit of the Zambezi Education Region face as a result of the automatic promotion policy. This study therefore, intends to establish the challenges these teachers face in the teaching of learners who have been automatically promoted to the new grade levels. It is vital to establish these challenges as they have a bearing on the academic performance of those who failed but promoted to their current grades as well as on the teaching itself.

The main research question is: What challenges do primary school teachers at the selected school in the Katima Circuit of the Zambezi Education Region face as a result of teaching learners who have been promoted automatically to their current grades? This study seeks answers to this question.

\section{Literature Review}

The researcher reviewed the literature by using the following themes: the meaning of the concept of automatic promotion, case studies of the system of automatic promotion and challenges of the automatic promotion system.

\subsection{The Meaning of the Concept of Automatic Promotion}

The US Department of Education (1999) defines the concept automatic promotion as the practice of passing students from grade to grade with their peers, even if they have not complied with the academic requirements, or met the performance standards of the key grades. Sometimes it is called "social" promotion because it is often carried out in the perceived interest of a student's social and psychological well-being.

According to Ellis-Christensen (2003), automatic promotion is the act of promoting students from one grade to the next even though they may not have demonstrated sufficient knowledge of the grade level standards. The impetus behind automatic promotion is that it is considered harmful to keep a learner "back", also known as retention, from a social point of view. In automatic promotion, the key issue is allowing a learner to continue to develop and learn in "relationships" with his/her peer group. Retention, on the other hand, is seen as a negative practice, which results in high drop-outs. Automatic promotion is the practice of promoting a student (usually, a general education student) to the next grade in spite of his or her low academic achievement in order to keep him/her with his/her social peers (Griffith, 2006; Leckrone, 1999; Ministry of Education, 1996). It is sometimes referred to as promotion based on "seat-time", or the amount of time the learner spent sitting in school, regardless of whether or not he/she learned the necessary knowledge, skills, values and attitudes.

In the article entitled, "Prevalence of Social Promotion", Albridge and Goldman (1999) define automatic promotion as the practice of promoting students to the next grade even though they have not acquired the minimum competencies expected of that grade. The reasons for automatic promotion are: fear that high 
failure rates would reflect poorly on the school and school personnel, pressure exerted by principals and parents to promote "ready" students, the standpoint that retention is ineffective, and the absence or inefficiency of effective educational alternatives to automatic promotion.

\subsection{Case Studies of the System of Automatic Promotion}

The introduction of the automatic promotion in the education systems of the world had been necessitated by the circumstances and contexts of the individual countries. In the United States, for example, it was the growing negative effects of retention on students' self-esteem (Westchester Institute for Human Services Research, 1999); and on the African continent, automatic promotion was introduced as a result of the demand to access to education soon after the achievement of political independence ( $N^{\prime}$ thogan, 2012).

However, automatic promotion is a global phenomenon. To substantiate the above statement, the implementation of the system on various continents is briefly related.

In South America, the example of Brazil is provided and in North America, the case of the United States of America is provided. On the European continent, the example of Great Britain is put forward. In Asia, India has been identified and the African example is South Africa.

\subsubsection{South America}

The General Education Act of 1996 (1996) paved the way for the introduction of automatic promotion policies in Brazil (Koppensteiner, 2010). Section 3 of Article 32 formally distinguishes two alternatives for education authorities to organize student progression: besides the conventional annual repetition regime to make low performing students repeat the grade, the alternative of automatic promotion was introduced, in which students' progress automatically to the next grade as low performers. Furthermore, the General Education Act of 1996 (1996) sets fundamental criteria on how to organize the promotion, such as $75 \%$ minimum attendance of the learners as a general requirement for the promotion.

\subsubsection{United States of America}

As stated earlier, the introduction of the automatic promotion system in the United States was necessitated by the growing negative effects of retention on students' self-esteem. Self-esteem in this context refers to a good opinion of one's own character and abilities. It is argued that if learners are retained in a given grade, the good opinion that they have about themselves might be affected negatively. However, the automatic promotion system came under severe criticism during the 1980s when concerns began to mount about the low student achievement and the increasing number of high school graduates who were ill-prepared for college and/or the workplace (Westchester Institute for Human Services Research, 1998). In response to the above, many of the state school systems passed strict promotion policies, often tied to student performance on standardized tests. 


\subsubsection{Great Britain}

Unlike in most parts of the world, where learners who failed to comply with the minimum promotion requirements are automatically promoted to the next grade through the policy of automatic promotion, in Europe, with specific reference to Great Britain, the decision of automatic promotion lies with the Class Council (Scholar Europaea, 2005). A Class Council is made up of all the teachers who have taught the learners during a given year, including teachers of Physical Education, Religious and Ethics. This is in accordance with the stipulations of a document entitled. "General Rules of the European Schools" which was approved by the Board of Governors of the European schools at a meeting in 2005 in Brussels. Article 57 of the document referred to above states that at the end of the school year, the Class Council shall decide whether learners are fit for promotion to the next grade.

\subsubsection{Asia}

In India, the National Policy on Education of 1986 set the stage for the central government to play an increasingly important role in primary education. According to Aggarwal (Aggarwal, 2012), through this policy, efforts have been made through successive Five-Year-Plans to achieve the target of $100 \%$ literacy through compulsory and free education for all children of the age group of 6 to 14 years. One of the measures to achieve this is to allow learners to progress from one grade to the next without satisfying the minimum promotion requirements of a given grade level.

However, the no-retention policy ushered in by the Right to Education Act of 1986 has attracted criticisms from many state governments arguing that it has led to a decline in academic commitment among students.

\subsubsection{Africa}

In post-Apartheid South Africa, the constructivist approach to teaching and learning and the adoption of Outcomes-Based Education (OBE) in 1998 have led to a great deal of confusion among teachers as well as heavy workloads in terms of continuous monitoring and recording (Organization for Economic Co-operation and Development, 2008). There has also been a move away from the formal, objective testing of learners. Apart from external summative testing at the end of a grade, where learners must have demonstrated competence in all eight learning areas (subjects), learners do not "fail" a subject or grade, which implies that learners ".. carry their lack of skills through with them to the next grade...", resulting in underachievement, frustration, and sometimes pre-mature school-leaving. According to the 2006 National Policy Assessments and Qualifications in Schools in the General Education and Training (GET) Band, all learners in Grades R-8"... should progress with their age cohort ...", and no learners should stay in the same phase for longer than four years (or five years in the case of the Foundation Phase, Grade R-2) unless the provincial head of departments has approved it. 


\subsection{Challenges of the Automatic Promotion System}

According to Lynch (2014), one of the challenges of this system is that learners are promoted without having acquired an adequate understanding of the prescribed academic content. While failure may be attributed to laziness; for some, it may be due to a failure to understand the concepts and content presented and assessed. If a learner who did not understand in one grade is promoted to the next and/or higher grade, he/she is likely to struggle even more in a more challenging academic subject or class. Learners who failed but are automatically promoted may also cause disturbances in the class, because they may feel that they know the learning material. Subsequently, their behavior might harm the educational process of the other younger learners.

Lawrence-Turner (2011) asserted that learners who fail but are then promoted automatically or socially, might develop what he termed learned "helplessness". Learned helplessness is the condition in which a learner does not feel that he/she is capable of achieving a goal, and, as a result, stops trying. If a learner sees that his/her teachers seem to accept his/her failing, he/she might stop trying.

Lowering the "floor" for achievement a particular grade level leads to the lowering of the "ceiling" as well, while a raised floor leads to a raised ceiling. Critics of the automatic promotion system charge that by promoting the unqualified, schools are adjusting their curriculum and assessment to the needs and standards of the learners, when, in fact, learners should be adapting to school standards. They see the function of the school as that of leading learners, not to follow them.

A number of studies singled out serious problems in the Namibian education system, especially those related to learners' low performance compared to other African countries, for example, the Southern and Eastern African Consortium for Monitoring Educational Quality (Ministry of Education, Sport and Culture, 2004). By comparing Namibia to other countries, especially those in southern Africa, the following research evidence was apparent: high levels of school failure and school drop-out; low levels of literacy and numerical skills; and poor results in tests as well as poor performance at secondary education level (Ministry of Education, Sport and Culture, 2004). Critics of the automatic or social promotion system largely attribute the above problems to the automatic promotion policy in Namibia since 1990. Commenting on the policy of automatic promotion in the Namibian education system, Abraham Iyambo, the then Minister of Education (NANSO, 2009) had this to say:

Automatic promotion introduced as part of the wholesome education reform after independence was aimed at giving slow learners a chance to adapt once they have moved to the next class. However, over the years learners have become complacent and disinterested in learning, thus heavily relying on the system of automatic promotion, knowing fully well that repeating a class twice was out of question. Automatic promotion has done more harm than good, as over the years it has been responsible for churning out half-baked learners onto the 
streets, subsequently leading to poor performance in schools and countless young unskilled Grade 10 dropouts. At my appointment I attempted to convince my cabinet colleagues to scrap the programme altogether in favor of the old system of "move to the next class when you are ready"(NANSO, 2009: p. 7).

\subsection{Conceptual Framework of the Challenges of the Automatic Promotion Policy}

The conceptual framework (Figure 1) of this study is divided into four categories: change, enrolment, demotivation and advanced work. Historically, people have been skeptical about change, particularly if it is a radical one. Furthermore, the retention policy has been in place since the colonial era, as such teachers find it difficult to adapt to the new policy (Corry, 2015). In this instance, the introduction of the automatic promotion policy was radically introduced in Namibia in line with the education reform after the attainment of independence. There is a challenge not only in terms of numbers of learners enrolling each year but with staffing as well. Even if some learners are to repeat classes there are not enough teachers to assist the weak learners (Muziransa, 2016). One of the many reasons for the introduction of the automatic policy is the psychological/emotional effect on children. On the other hand, this policy can demotivate learners in that they do not feel the need to display a competitive spirit. Learners are shielded from any pressing challenge to do better and the standard and quality of education are compromised because learners feel that regardless of whether they do well or

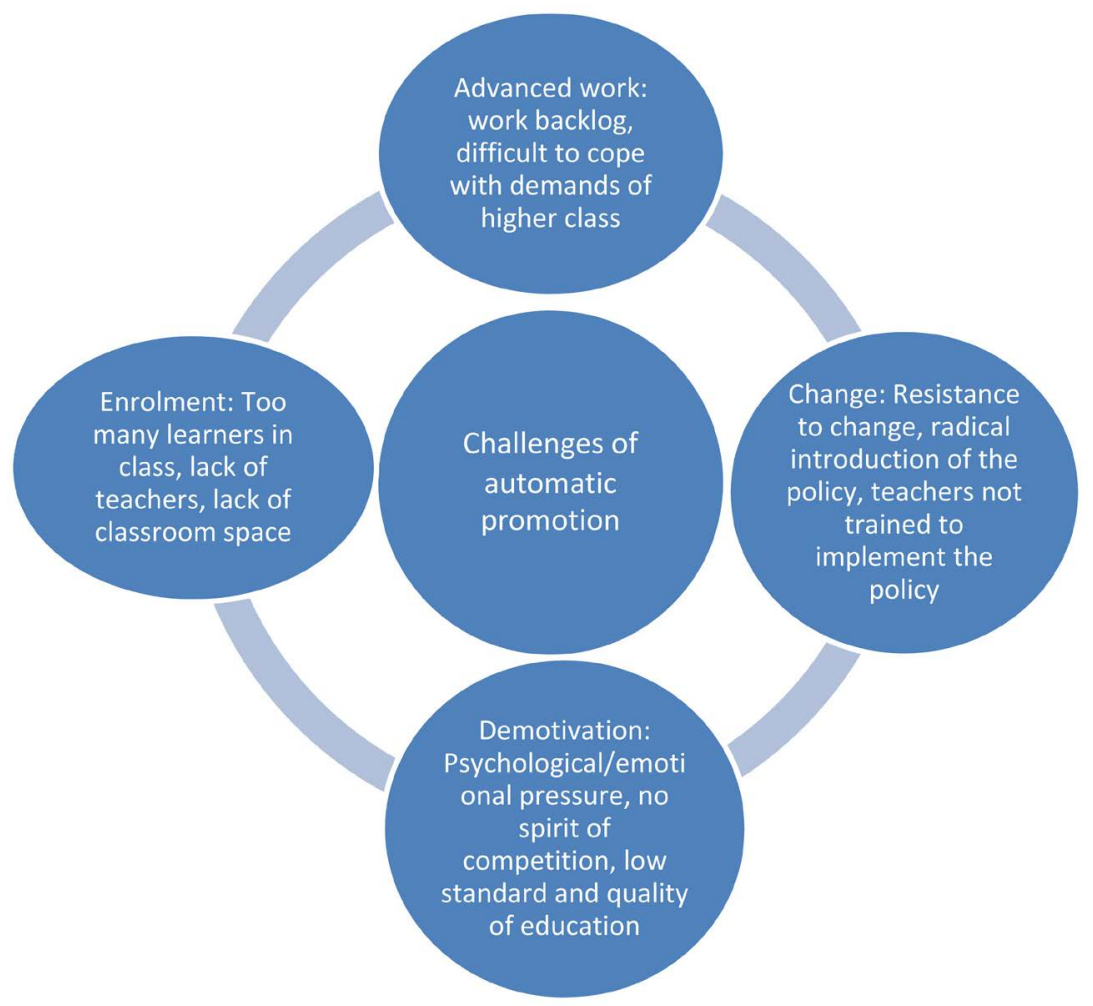

Figure 1. Challenges of the automatic promotion policy-a conceptual framework. 
poorly, they will, as a matter of policy, be promoted to the next grade. They do not see the need to work hard (Corry, 2015). On advanced work, the challenge is the fact that when a learner goes into a higher class, he/she will be tasked with advanced work and his/her ability to cope will largely depend on the mastering of the programme in the previous class because the school curriculum is one of continuity. When a learner repeats a class, he/she may be able to catch up as some learners are slow and repeating may actually benefit them.

\section{Research Methodology}

\subsection{Research Design}

This research study used a qualitative design. The purpose of which is to gain insight into the area of research and not necessarily to make generalizations of the findings. The validity, meaningfulness, and insights generated from qualitative inquiry have more to do with information-richness of the cases selected and the observational/analytical capabilities of the researcher than with sample size (Patton, 1990).

School selection: The school that was involved in the study is an urban school in the Katima Circuit, where four (4) teachers who are currently teaching or have taught learners who have been promoted automatically to the next grades were interviewed.

\subsection{Data Collection Method}

Interviews as a data collection method were used for this study. A total of four (4) primary school teachers were interviewed and were selected on the basis that they have experience in teaching learners who have been automatically promoted to their new grades; either they are currently teaching such learners or they once taught this group of learners. A focus group discussion was used guided by an interview schedule. Focus groups are a means of better understanding how people feel or think about an issue, product or service. Participants are selected because they have certain characteristics in common that relate to the topic of the focus group (De-Vos, 2004).

\subsection{Data Analysis}

The analysis of data was done by identifying salient themes, recurring ideas, and patterns of belief. These themes, ideas, and patterns of belief were classified into categories and were interpreted to make sense of the data collected, the lessons learned and what should be reported in the study. The researcher used $\mathrm{T} 1 \mathrm{for}$ the first teacher interviewed, T2 for the second teacher, T3 for the third teacher and T4 for the fourth teacher.

\section{Presentation of Findings and Discussion}

The major findings in this study are poor performance, truancy, bullying other learners and no time to assist other learners. 


\subsection{Poor Academic Performance}

Poor performance on the part of learners in almost all subjects was reported by all those interviewed. One of the interviewees (T2) said these learners do not perform well in class and they do not seem to care about school.

During lessons these learners are the ones who fail class work activities, do not do their homework, and they are absent-minded all the time. They fail to calculate even very basic sums. Their handwriting is good but what they write is rubbish. There are lots of gaps in terms of knowing the subject content. They are very active outside (T2).

According to this teacher, he gets demotivated because no matter how much effort he puts in the lesson, these learners' performance does not improve. $\mathrm{He}$ said these learners behave that way because they know that even if they fail they will be promoted to the next grade just like their fellow classmates-this promotes laziness.

Another teacher, (T1) said that poor performance contributes to the high number of school drop-outs. If a learner repeats almost all phase levels chances are that such a learner will leave school. He or she will be shy because other learners will ridicule him or her and the only option he/she has is to drop out of school.

\subsubsection{Truancy}

When asked about the challenges she faces in teaching learners who have been promoted automatically, 73 explained that "I have observed that learners who have been promoted automatically miss classes too much compared to those who passed their previous grades" (T3). She attributed their poor performance in class to truancy.

"I always organize extra classes, which is called compensatory teaching, specifically for slow learners and those who are truant, of whom the majority are the automatically promoted learners, but still many do not show up for classes", T4 responded as her contribution to the issue of truancy in her class.

The majority of learners who dropped from school in my class this year are the ones who have been wheel-chaired into the new grade. They are five in total only one passed straightaway his previous grade. This group of learners is a problem $(\mathrm{T} 1)$.

\subsubsection{Bullying Other Learners}

Automatically promoted learners bully other learners in class. When a task is given in class, these learners do not do the work themselves, instead, they give the clever ones to do the work for them or they demand correct answers and then copy these answers into their exercise books. They threaten the clever ones if they dare telling the teacher.

They are the trouble-makers, they do not care about school. This contributes to the failure of learners. Too many learners fail (T2). Their participation in class activities is very low and even when they know the answer they will not raise up 
their hands but if one gets the answer correct, they will shout "You got it, world record" (T4).

\subsubsection{No Time to Assist Other Learners}

A lot of time is spent on one learner who is struggling to understand what you are teaching at the expense of the whole class, is also a challenge we face in teaching learners who have been automatically promoted to the next grade. This learner is learning something for which he does not have an idea about. He should have mastered some basics of the subject in the previous grade but then promoted to the next grade empty-headed. This is a challenge for the new teacher to teach the content of the previous grade and again teach the content of the new grade. This is what we are going through because of the policy of automatic transfer (T4).

\subsection{Suggestions on the Policy of Automatic Promotion of Learners}

All the four teachers interviewed were of the opinion that the Ministry of Education, Arts and Culture should revise the policy of automatic promotion. Learners who fail a given grade should repeat the grade no matter how many times one repeats. They argued that the more learners repeat the more they master what they learn. To them, automatic promotion policy has failed.

\subsection{Discussion}

\subsubsection{Poor Performance}

The research study discovered that poor performance of automatically promoted learners is one of the challenges primary school teachers at the selected face. These learners struggle to cope with the demands of the grades in terms of mastering subject content. They have a backlog of work from the previous grade which they did not pass plus the work of the new grade. Compounded with this is the fact that learners know that even if they fail, they will be promoted automatically to the next grade level. Teachers get demotivated to teach under such circumstances. Learners who are automatically or socially promoted have not acquired an adequate understanding of the prescribed academic concepts and content presented and assessed. If a learner who did not understand the concepts in one grade is promoted to the next and/or higher grade, he/she is likely to struggle even more in a more challenging academic subject or class.

Truancy: The findings also revealed that truancy was another challenge of the automatic promotion policy. Automatically promoted learners miss a lot of classes compared to other learners and they also drop out of school in bigger numbers comparatively speaking. They lack the urge and appetite for learning and school. When learners get "tired" of repeating a grade some of them would leave school and join their family activities (Shilongo, 2004).

Bullying other learners: The study also concluded that bullying of other learners is another challenge primary school teachers at the selected school face. 
Learners who failed but were promoted automatically may also cause disturbances in the class because they feel that they know the learning material. Consequently, their behavior might harm the educational progress of the other and younger learners. Bullying is an aggressive behavior characterized by repetition and imbalance of power with less powerful persons being repeatedly abused (Ken, 2003; Rose, 2010). Learners who failed but were then automatically or social promoted might develop what he termed "learned helplessness". Learned helplessness is the condition in which a learner feels that he/she is not capable of achieving a goal, and as a result, stops trying (Lawrence-Turner, 2011).

\subsubsection{No Time to Assist Other Learners}

The study revealed that teachers spend a great deal of time to assist learners who fail to copy with learning in the new grades. They give remedial teaching to assist such learners to catch up with the rest of the class. Despite this effort on the part of teachers many of the automatically promoted learners do not attend these sessions. Because of these extra classes teachers do not have enough time to attend to each learner's learning needs. This point is emphasized by Lamb and Rice (2008) when he argues that automatic promotion forces teachers to deal with under-prepared learners while trying to teach the prepared ones.

\section{Conclusion}

Teaching learners who have been promoted to new grades without meeting the minimum pass requirements as stipulated by the education authorities is a serious challenge on the part the teachers at the selected school. These learners develop a negative attitude towards learning, the school, teachers, and fellow learners coupled with the fact they know that even if they fail they will be automatically pushed to the next grade level as a matter of policy. Teachers are frustrated because of teaching learners who do not seem to care about schooling which has a negative impact on their morale.

Since the issue under investigation is a policy issue and therefore, there is little teachers can do about it. It is recommended that more studies be done on the topic, hoping that policymakers may consider reviewing the policy in future.

\section{Conflicts of Interest}

The authors declare no conflicts of interest.

\section{References}

Aggarwal, D. (2012). History and Development of Elementary Education in India. New Delhi: Sarup and Sons.

Aldridge, R., \& Goldman, C. (1999). Prevalence of Social Promotion. New York: Bacon Prentice.

Corry, J. (2015). The Value of Education. Chronicle, 12, August 3.

Department of National Education (1980). National Assessment Policy for Schools in South West Africa. Windhoek: Government Print. 
Department of National Education (1980). National Education Act, No. 30. Windhoek: Government Print.

De-Vos, A. (2004). Research at Grass Roots-For the Social Sciences and Human Service Professionals. Paarl: Paarl Print.

Ellis-Christensen, T. (2003). What Social Promotion Is. http://wisegeek.com/what-is-social-prmotion.htm

Griffith, M. (2006). Social Promotion in Schools. New York: Atlanta Publishers.

Ken, S., \& Rose, J. (2010). Ending Social Promotion. Philadelphia, PA: Palmer Press.

Koppensteiner, C. (2010). General Education Act of 1996. Brasilia: LDB.

Lamb, S. and Rice, S. (2008). Effective Intervention Strategies for Students at Risk of Early Leaving. Centre for Post-compulsory Education and Lifelong Learning The University of Melbourne.

http://samordningsforbund.se/wp-content/uploads/sites/3/2014/06/rapport_university _of_melborne_080501.pdf

Lawrence-Turner, J. (2011). Social Promotion Puts Students on Rough Path: Passage Leaves Teachers, Parents with Tough Decisions to Make. The Spokesman Review. http://www.spokesman.com/stories/2011/oct/16/a-pupils-right-of-passage/

Leckrone, M. (1999). Retention Realities and Educational Standards. Children and School, 54, 35-38.

Lynch, M. (2014). Alternatives to Social Promotion and Retention. Interchange, 44, 291-309. https://doi.org/10.1007/s10780-014-9213-7

Mbumba, N., \& Noise, P. (1988). Namibia in History. London: Zed Books.

Ministry of Education (1996). General Education Act. Sao Paolo: Government Printer.

Ministry of Education (2005). Requirements for Promotion of Learners in Grades 1-9 and 11 and Compulsory Compensatory Teaching. Okahandja: National Institute for Educational Development.

Ministry of Education, Sport and Culture (2004). Southern and Eastern Africa Consortium for Monitoring Educational Quality: SACMEQ II Report-A Study of the Conditions of Schooling and the Quality of Primary Education in Namibia. Blantyre: Government Print.

Muziransa, J. (2016). Retention vs. Promotion. New York: Government Printers.

N’thogan, C. (2012). Promotion and Upgrading in the Ghana Education Service. http://www.modernghana.com/promotion-and-upgrading-in-the-ghana-education-ser vice

NANSO (2009). NANSO's Position on the Automatic Promotion Policy. Windhoek: NBC.

Organization for Economic Co-Operation and Development (2008). Review of National Policies for Education-South Africa. Pretoria: Corrigenda.

Patton, M. (1990). Qualitative Evaluation and Research Methods. New York: SAGE.

Pupkewitz, H. (2006). On the Education Crisis. The Namibian, 31, March 7.

Rose, D. (2010). Childhood Bullying and Teasing: What School Personnel, and Other Professionals and Parents Can Do. Alexandria: American Counseling Association.

Scholar Europaea (2005). General Rules of the European Schools as Approved by the Board of the European Schools on 1st and 2nd February. Brussels.

Shilongo, E. (2004). A Historical Overview of Educational Assessment in Namibia (pp. 25-27). Windhoek: Reform Forum. 
US Department of Education (1999). Re-Thinking Social Promotion Policy. Washington DC: Government Printers.

Westchester Institute for Human Services Research (1999). The Balanced View. Social Promotion and Retention.

Zeichner, K. (1996). Reflective Teaching: An Introduction. Hillsdale, NJ: Lawrence Erlbaum Associates. 